Available online on 15.11 .2015 at http://jddtonline.info
Journal of Drug Delivery and Therapeutics
Open access to Pharmaceutical and Medical research
(c) 2015, publisher and licensee JDDT, This is an Open Access article which permits unrestricted noncommercial use, provided the original
work is properly cited

\title{
RESEARCHARTICLE
}

\section{EFFECT OF NITROGEN SOURCE FOR THE BIOSYNTHESIS OF XYLANASE FROM ASPERGILLUS TAMARII}

\author{
Dhulappa $\mathrm{A}^{1}$, *Lingappa $\mathrm{K}^{2}$ and Siddalingeshwara $\mathrm{K} \mathrm{G}^{3}$ \\ ${ }^{1}$ Department of Microbiology, Maharani’s Science College for Women, Bangalore, India \\ ${ }^{2}$ Department of Studies in Microbiology, Gulbarga University, Gulbarga, India \\ ${ }^{3}$ Scientific \& Industrial Research Centre, Bangalore, India
}

Received 11 Oct 2015; Review Completed 02 Nov 2015; Accepted 04 Nov 2015, Available online 15 Nov 2015

\begin{abstract}
The main aim of the study is to enhance the biosynthesis of xylanse by incorporating nitrogen sources (both organic and inorganic). Recently, xylanases have expanded their use in many processing industries, such as pulp and paper, food and textile to newer needs such as biofuel production. This study were taken up to the enhance the biosynthesis of xylanase by supplementation of organic nitrogen and inorganic nitrogen sources were employed in range of $0.25 \%$ to $1.25 \%$. The organic nitrogen source were supplemented are peptone, yeast extract and beef extract and inorganic nitrogen sources are ammonium sulphate, ammonium chloride and ammonium nitrate. The yeast extract and ammonium nitrate were yielded higher xylnase production and showed 5.56 IU and 5.79 IU
\end{abstract}

Key words: Xylanase, submerged fermentation, yeast extract, ammonium nitrate and assay.

\section{INTRODUCTION}

Xylan is a noncrystalline complex polysaccharide consisting of a backbone of $\beta$-D-1, 4linked xylopyranoside units substituted with acetyl, glucuronosyl, and arabinosyl side chains ${ }^{1}$. Xylans are the main carbohydrate in the hemicellulosic fraction of vegetable tissues and form an interface between lignin and the other polysaccharides. The polysaccharides are mainly found in secondary plant cell walls, and their characteristic of adhesion helps to maintain the integrity of the cellular wall ${ }^{2}$. The interest in cellulase free xylanases has focused on pulping and bleaching processes, in which chlorine $(\mathrm{Cl} 2)$ and hypochlorine (ClO2) for biobleaching can be reduced. Naturally occurring microbial strains capable of secreting xylanases free of cellulase activity would be attractive for such applications. Xylanases enhance the cleaving of reprecipatated xylan formed on the outer surfaces of the cellulose fibers after pulping ${ }^{3}$. This caused increased permeability of the pulp fibers to the bleaching chemicals and allows the passage of larger fragments of residual lignin out of the pulp.

Xylanolytic enzymes from microorganisms have attracted the attention for the last few decades, particularly because of their biotechnological potential in various industrial processes such as food, feed, baking, pulp and paper industries ${ }^{4 \& 5}$ Biobleaching and bioprocessing of pulps using xylanases is one of the most suitable biological applications in the pulp and paper industry. ${ }^{6}$ gave an overview of fungal xylanases and showed that the enzyme can be produced by a number of microorganisms including bacteria, yeasts and filamentous fungi including Trichoderma, Bacillus, Cryptococcus, Aspergillus, Penicillium, Aureobasidium, Fusarium, Chaetomium, Phanerochaete, Rhizomucor, Humicola, Talaromyces etc. These enzymes havebeen widely detected in fungi and bacteria ${ }^{7-9}$

Filamentous fungi are attracting greater attention than bacteria as potential sources of plant cell wall hydrolyzing enzymes such as xylanases because they secrete high levels of the enzymes into the culture medium ${ }^{10}$. Filamentous fungi are useful producer of xylanases from the industrial point of view. The reasons are many fold - they are non pathogenic, capable of producing high levels of extra cellular enzymes and they can be cultivated very easily.

The aim of the present study involves the process should economize by using nitrogen sources for the enhanced production of xylanase employing Aspergillus tamarii through solid state fermentation using wood chips as a fermenting medium.

*Corresponding Author: Dr. Lingappa $K$ Professor, Department of Microbiology, Gulbarga University, Gulbarga, India E-mail: lingappak1@ rediffmail.com 


\section{MATERIALS AND METHODS}

\section{Fungal strain}

The Aspergillus tamarii strains were isolated from different soils, rotten vegetables and wood chips from different regions in and around Bangalore and tentatively identified in the laboratory.

\section{Screening of xylanase producers and solid state Fermentation Medium}

Aspergillus tamarii strains were screened for their xylanase activity by plate assay ${ }^{9}$ and Aspergillus tamari KLD 02 were used for further studies. The selected Aspergillus tamari KLD 02 were cultured on production medium, the medium of fermentation is solid state. The substrate used for the production is wood chips. The optimized condition of the fermentation medium is as follows. The moisture content $65 \%$, pH 5 temperature $35^{\circ} \mathrm{C}$ and inoculums size is of $1.0 \mathrm{ml}$.

\section{Influence of Organic and inorganic nitrogen source for the biosynthesis of Xylanase}

The organic nitrogen sources were supplemented in the range of $0.25 \%$ to $1.25 \%$ with an increment of $0.25 \%$.The organic nitrogen source are yeast extract, beef extract and peptone. The inorganic nitrogen sources were supplemented to the production medium those are ammonium sulphate, ammonium nitrate and ammonium chloride in the range of $0.025 \%$ to $0.125 \%$ with optimized conditions.

\section{Extraction of Xylanase}

One $1 \mathrm{gm}$ of the samples was withdrawn periodically at $24 \mathrm{hrs}$ in aseptic condition. The extract were crushed with $10 \mathrm{ml}$ of distilled water and filtered through Whatman filter No.1. The clear extract was centrifuged at 2000-3000 rpm for $15 \mathrm{~min}$, supernatant were used as enzyme preparation. Thus prepared crude enzyme was used for assay of xylanase.

\section{Assay of Xylanase}

The xylanase activity was determined by measuring the release of reduced sugars from oat spelt Xylan $(1 \% \mathrm{w} / \mathrm{v})$ by dinitrosalicylic acid method ${ }^{11}$. The enzyme solution $(0.5 \mathrm{ml})$ and 0.5 substrate (xylan $1 \%$ w/v) along with $1 \mathrm{ml}$ of buffer were taken in a test tube, the tubes were then allowed to stand at room temperature for $10 \mathrm{mins}, 3 \mathrm{ml}$ of dinitrosalicylic acid was added to arrest the reaction. After the addition of dinitrosalicylic acid, the tubes were placed in boiling water bath for $10 \mathrm{~min}$. The color which had developed was read colorimetrically at $540 \mathrm{~nm}$. A blank test tube was prepared by adding dinitrosalicylic acid prior to the addition of enzyme to the test tubes.

\section{International unit (IU)}

One unit of xylanase was defined as the amount of enzyme required to release $1 \mu \mathrm{mol}$ of xylose from oat spelt xylan in one minute under standard assay conditions.

\section{RESULTS AND DISCUSSION}

Thirty Aspergillus tamarii isolates were isolated from different soils, rotten vegetables and wood chips samples from in and around Bangalore. All thirty isolates were named serially Aspergillus tamarii KLD1KLD30 and used for screening of xylanase production by plate assay method. Out of thirty isolates Aspergillus tamarii KLD 02 was showed maximum enzyme hydrolytic zone.

Fungal isolates were identified as Aspergillus tamarii in the laboratory. All thirty strains of Aspergillus tamarii produced enzyme hydrolytic zone on xylan plate medium were selected from the soils, rotten vegetables and wood chips sample. Of the thirty isolates Aspergillus tamarii KLD 02 was considered to be the best and high xylanase producing strain.

The organic and inorganic nitrogen sources were used for the production of xylanase through solid state fermentation. Among the organic nitrogen source peptone, yeast extract and beef and inorganic nitrogen ammonium sulphate, ammonium chloride and ammonium nitrate were used. The concentration was used in the range of 0.25 to $1.25 \%$. Among the organic nitrogen source yeast extract showed the better source for the synthesis of xyalanase at $1.0 \%$ level and it showed 5.56 IU as highest xylanase and 2.6 $7 \mathrm{IU}$ is the lowest biosynthesis of xylanase at $72 \mathrm{hrs}$ of fermentation. The beef extract and peptone were showed $4.44 \mathrm{IU}$ and $4.28 \mathrm{IU}$ at $1.0 \%$ at $72 \mathrm{hrs}$ of fermentation periods and graphical representations were showed in Fig 1- 3 for organic sources.

The inorganic nitrogen sources are ammonium sulphate, ammonium chloride and ammonium nitrate were used and Fig 4, 5 and 6 represented the xylanase production. Ammonium nitrate showed 5.79 IU showed maximum xylanase at $0.025 \%$ and lowest xylanase at $2.56 \mathrm{IU}$ at $72 \mathrm{hr}$ fermentation period. By supplementing $0.10 \%$ of the ammonium chloride and ammonium sulphate also showed $3.98 \mathrm{IU}$ and 3.46 IU xylanase synthesis was found at $72 \mathrm{hr}$ of fermentation period ${ }^{12}$.

Data were reported that the organic nitrogen source i.e yeast extract was showed better yield (3.56 IU) by using wheat bran as substrate by using penicillium oxalicum and also showed sodium nitrate as inorganic nitrogen source. Similar reports were also highlighted by Purkarthofer et al., ${ }^{13}$, Lemos et al. ${ }^{14}$ and Bakri et al., ${ }^{15}$. Kanimozhi and Nagalakshmi ${ }^{16}$ were studied the organic and inorganic nitrogen sources for xylnase synthesis by using Aspergillus niger through solid state fermentation and concentration is $0.075 \%$. Xiuting $\mathrm{Li}$ et al., ${ }^{17}$ were highlighted organic and inorganic nitrogen source at the rate of $1.5 \%$ by using Streptomyces chartreusis. In the present study results are coincides with the results of Kanimozhi and Nagalakshmi ${ }^{16}$. 


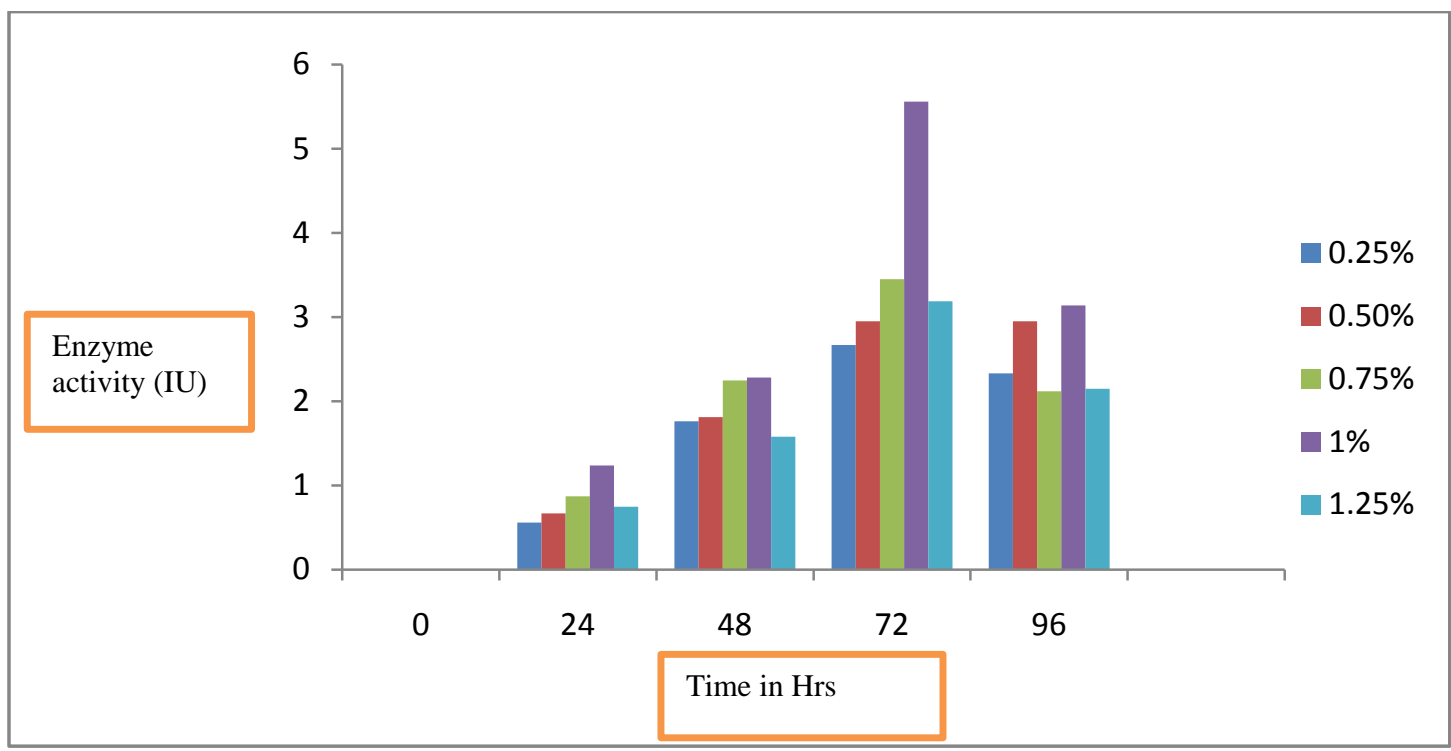

Figure 1: Effect of yeast extract on biosynthesis of Xylanase

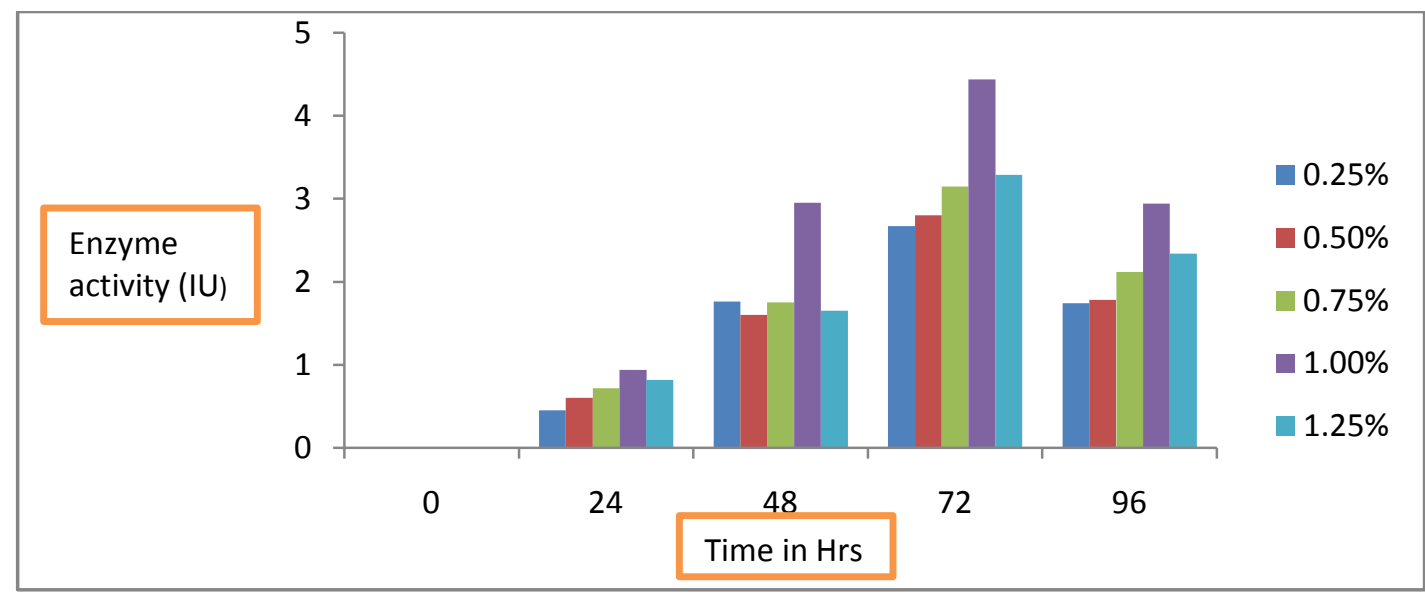

Figure 2: Effect of beef extract on biosynthesis of Xylanase

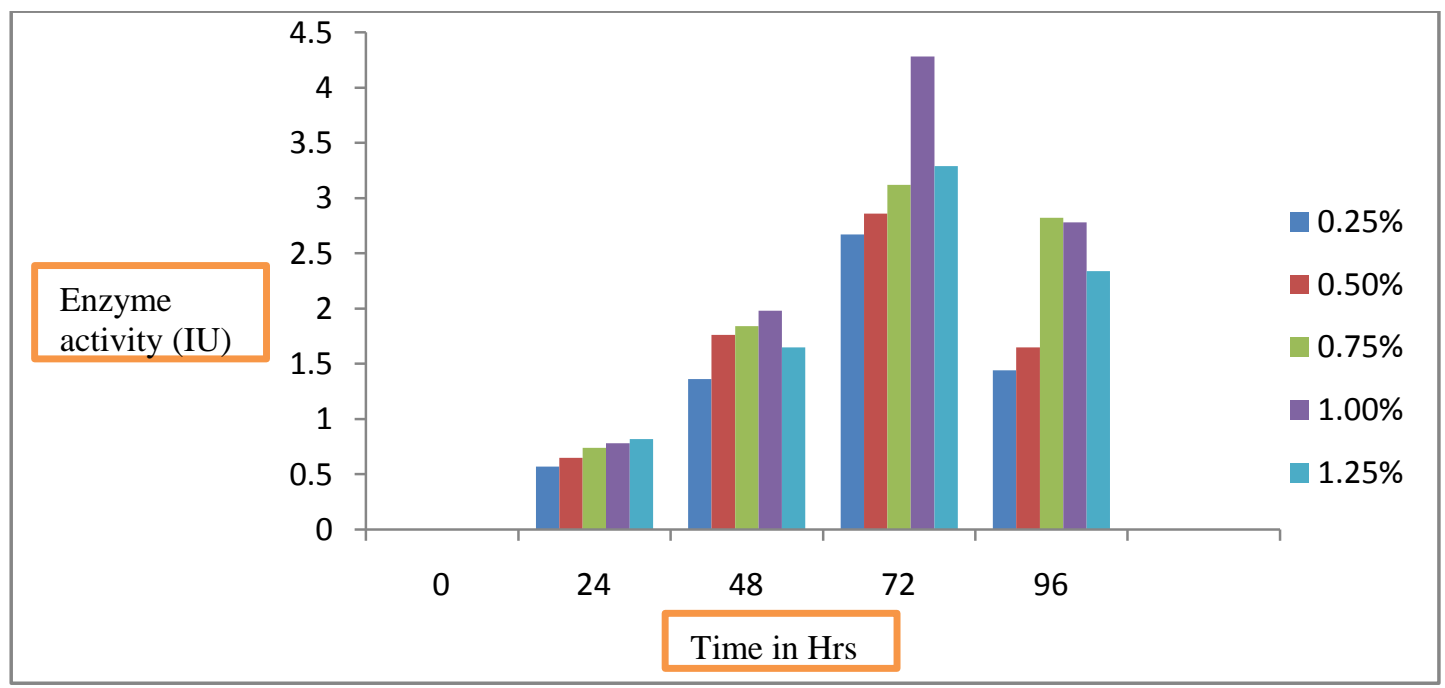

Figure 3: Effect of peptone on biosynthesis of Xylanase 




Figure 4: Effect of Ammonium sulphate on biosynthesis of Xylanase



Figure 5: Effect of Ammonium chloride on biosynthesis of Xylanase

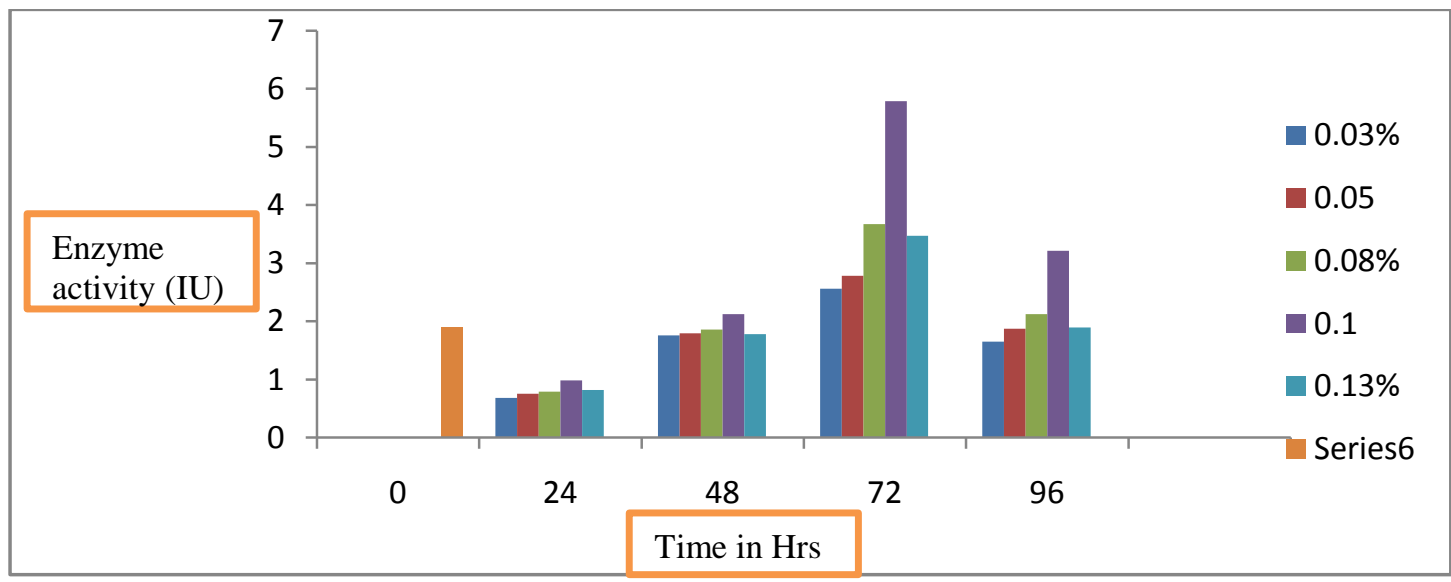

Figure 6: Effect of Ammonium nitrate on biosynthesis of Xylanase

\section{CONCLUSION}

Among the thirty isolates Aspergillus tamarii KLD 02 were showed better xylanase production. The enhanced level of biosynthesis of xylanase observed by supplementation of organic and inorganic nitrogen sources and they have showed better yield under solid state fermentation by using wood chips. 


\section{REFERENCES}

1. Grange DC, Claeyssens M, Pretorius IS, van Zyl WH. Degradation of Xylan to D-Xylose by recombinantSaccharomyces cerevisiae coexpressing the Aspergillus niger $\beta$-Xylosidase $(x \ln \mathrm{D})$ and the Trichoderma reeseiXylanase II (xyn2) genes. Applied and Environmental Microbiology. 2001;67(12):5512-5519.

2. Goulart AJ, Carmona EC, Monti R. Partial purification and properties of cellulase-free alkaline xylanase produced by Rhizopus stolonifer in solid-state fermentation. Brazilian Archives of Biology and Technology. 2005;48(3):327-333.

3. Wong K.K.Y., Tan, L.U., and Saddler, J.N. "Multiplicity of P1,4-xylanase in microorganisms, functions and applications", Microbiol. Rev. 1988, vol52, pp305- 317.

4. Arulanandham TV and Palaniswamy M. Production of xylanase by Aspergillus nidulans isolated from litter soil using rice bran as substrate by solid state fermentation. World journal of pharmacy and pharmaceutical sciences. 2014, 3(7):1805- 1813.

5. Beg QK, Kapoor M, Mahajan L et al. Xylanases from fungi: properties and industrial applications. Appl Microbiol Biotechnol. 2005, 67:577-591.

6. Haltrich D, Nidetzky B, Kulbe KD, Steiner W, Zupaneie S. Production of fungal xylanases. Bioresour. Technol. 1996, 58: 137- 161.

7. Lee SF, Forsberg CW, Gibbins LN. Xylanolytic activity of Clostridiumacetobutylicum, Appl. Environ. Microbiol. 1985, 50: 1068-1076.

8. Marques SL, Alves S, Ribeiro FM, Gírio MT, Amaral C. Characterization of a thermotolerant and alkalotolerant xylanase from a Bacillus sp. Appl. Biochem. Biotechnol. 1998, 73: 159-172

9. Shao W, Wiegel J. Purification and characterization of a thermostable-xylosidase from Thermoanaerobacter ethanolicus. J.Bacteriol, 192, 174: 5848-5853.
10. Berry and paterson. Xylanase production by Aspergillus niger ANL 301 using agro- wastes., African J.Biotechnol. 1990, 6(14):1710-1714.

11. Miller, and Gail Lorenz, Use of dinitrosalicylic acid reagent for determination of reducing sugar". Anal. Chem. 1959, 31 (3), 426-428.

12. Muthezhilan R, Ashok R and Jayalakshmi S. Production and optimization of thermostable alkaline xylanase by Penicillium oxalicum in solid state fermentation. African Journal of Microbiology Research pp. 2007, 020-028,

13. Purkarthofer H, Sinner M Steiner W. Cellulase-free xylanase from Thermomyces lanuginosus: optimization of production in submerged and solid-state culture. Enzyme Microbiol. Technol. 1993, 15: 677-682.

14. Lemos JLS, Fontes MCA, Pereira NJ. Xylanase production by Aspergillus awamori in solid-state fermentation and influence of different nitrogen sources. Appl. Biochem. Biotechnol. 2001, (93): 681-689.

15. Bakri Y, Jacques P, Thonart P (2003). Xylanase production by Penicillium canescens 10-10c in solid-state fermentation. Appl. Biochem. Biotechnol. pp. 105-108, pp. 737-747.

16. Kanimozhi K, Nagalakshmi PK. Xylanase production from Aspergillus niger by Solid State Fermentation using Agricultural waste as substrate.Int.J.Curr.Microbiol.App.Sci, 2014, 3(3): 437-446.

17. Xiuting Li, Baoguo Sun1, Jin Zhao, Yuegang Lv, Hongxia Song E. Li and Yunping Zhu.(2011). Production and improved bleaching abilities of a thermostable xylanase from a newly isolated Streptomyces chartreusis strain. African Journal of Biotechnology Vol. 10(64), pp. $14132-14142$ 